\title{
Dynamic Modal Analysis of Vertical Machining Centre Components
}

\author{
Anayet U. Patwari, ${ }^{1}$ Waleed F. Faris, ${ }^{2}$ A. K. M. Nurul Amin, ${ }^{1}$ and S. K. Loh $^{3}$ \\ ${ }^{1}$ Department of Manufacturing and Materials Engineering, Faculty of Engineering, International Islamic University Malaysia (IIUM), \\ P.O. Box 10, 50728 Kuala Lumpur, Malaysia \\ ${ }^{2}$ Department of Mechanical Engineering, Faculty of Engineering, International Islamic University Malaysia (IIUM), \\ P.O. Box 10, 50728 Kuala Lumpur, Malaysia \\ ${ }^{3}$ OYL R \& D Research, Faculty of Engineering, International Islamic University Malaysia (IIUM), \\ P.O. Box 10, 50728 Kuala Lumpur, Malaysia
}

Correspondence should be addressed to Waleed F. Faris, waleed@iiu.edu.my

Received 26 March 2009; Accepted 13 October 2009

Recommended by Mohammad Tawfik

The paper presents a systematic procedure and details of the use of experimental and analytical modal analysis technique for structural dynamic evaluation processes of a vertical machining centre. The main results deal with assessment of the mode shape of the different components of the vertical machining centre. The simplified experimental modal analysis of different components of milling machine was carried out. This model of the different machine tool's structure is made by design software and analyzed by finite element simulation using ABAQUS software to extract the different theoretical mode shape of the components. The model is evaluated and corrected with experimental results by modal testing of the machine components in which the natural frequencies and the shape of vibration modes are analyzed. The analysis resulted in determination of the direction of the maximal compliance of a particular machine component.

Copyright ( 92009 Anayet U. Patwari et al. This is an open access article distributed under the Creative Commons Attribution License, which permits unrestricted use, distribution, and reproduction in any medium, provided the original work is properly cited.

\section{Introduction}

The dynamic behavior of a structure in a given frequency range can be modeled as a set of individual modes of vibration. The parameters that describe each mode are natural frequency or resonance frequency (modal) damping mode shape; these are called the modal parameters. By using the modal parameters to model the structure, vibration problems caused by these resonances (modes) can be examined and understood [1-4]. In addition, the model can subsequently be used to come up with possible solutions to individual problems. Vibration occurring on machine tools has been being a serious problem for engineers for more than one century. Undesired relative vibrations between the tool and the work-piece jeopardize the quality of the machine surfaces during cutting.

Modal analysis is a process whereby a structure may be defined in terms of its natural characteristics which are the frequency, damping, and mode shapes-its dynamic properties. Since all bodies have both mass and elasticity, they are capable of vibration. Therefore, most engineering structures and machines experience some form of oscillatory motion. To better understand any structural vibration problem, the resonances of a structure need to be identified and quantified. A common way of doing this is to define the structure's modal parameters. Static and dynamic deformations of machine tool, tool holder, and cutting tool play an important role in tolerance integrity and stability in a machining process affecting part quality and productivity. Experimental modal analysis has rapidly developed as an area of science in last few years and has become as efficient as the finite element method. It is an experimental approach for solving technical problems which is a means to estimate or evaluate modal properties of a mechanical structure. Modal analysis is vital to understanding and optimizing the inherent dynamic behavior of 
structures, leading to lighter, stronger, and safer structure with better performance. In modal analysis, a mathematical model of a structure's dynamic behavior is obtained. The mathematical model consists of a set of mode shapes each with an associated natural frequency and modal damping. These modal parameters provide a complete description of the structure's dynamic behavior. Baker and his coresearchers used finite element method to analyze the instability of machining process [5]. They created a structural model of machine tool system using the commercial FE code, ANSYS, without any experimental tests. In this model the bed of machine tool, spindle, and tool holder, as steel blocks, are modeled. The integrity of these models is not confirmed by experimental results. In another research with the aim of analysis of chatter phenomena, the tool's natural frequencies and the shape of their vibration modes were obtained by modal testing results. In this case the variations of acoustic emission signal during chatter are analyzed, so that it can be used for chatter detection in machining duration [6]. Many researchers [7-9] tried to analyze the static and dynamic analysis of the structure involved in machining system by resting using stiffness measurements and modal analysis. Talantov and Amin have observed that chatter arising during turning is a result of resonance, caused by mutual interaction of the vibrations due to serrated elements of the chip and the natural vibrations of the system components, for example, the spindle and the tool holder [10-12]. The chatter phenomena were indicated by the some of the researchers as a resonance effect where system components played a vital role. So it is important to extract the accurate mode shape of the dominating components of machine structure to identify the chatter formation causes. The paper is focused at dynamic properties of a vertical milling machine, namely, at the resonance frequencies and vibration shapes of a vertical machining centre components. All this properties are identified by measurements. The machine tool vibration was excited by impulse force and a response of excited vibration was recorded. The measurement points for vibration were selected at the different location of spindle, tool, and collet.

\section{Simplified Modal Analysis of Milling Machine}

Aiming to investigate the vibration phenomena occurring occasionally at the different components of milling machine experimental and analytical modal analyses were performed. The study focused on extracting the mode shape of the dominating components of the milling machine in order to ensure resonance phenomena as a cause of chatter. In a first step the significant eigen-frequencies with corresponding mode shapes were obtained by means of an experimental modal analysis (EMA). Subsequently, the dynamic behavior of the machine components was simulated using an ABAQUS FE model. The comparison of the eigenfrequencies based on FE calculations with their experimental counterparts proved in general quite satisfactory correlation.

\section{Experimental Modal Analysis}

3.1. Measurement Hardware. A vibration measurement generally requires several hardware components. The basic hardware elements required consist of a source of excitation, called an exciter (Impulse hammer), for providing a known or controlled input force to the structure, a transducer to convert the mechanical motion of the structure into a electrical signal, a signal conditioning amplifier, and an analysis system in which modal analysis program resides.

The schematic diagram of hardware used performing in a vibration test is shown in Figure 1. The different equipments that have been used are listed as follows: Pulse Front-end (Data Acquisition), Impact Hammer, USB Dongle, Accelerometers, Impact Hammer cable, Accelerometer cables, Pulse Front-End Power Supply, TCP/IP Cross Cable, and Bee's wax.

3.2. Test Procedures. The different milling machine components were identified which play a dominating role for the chatter generation. The natural frequency of the different components was measured using modal analysis under static and dynamic conditions and consequently the different mode shapes were identified. Initially excited frequencies were monitored during the operational mode under noload condition. It is easy to record a response in vibration during machining but almost impossible to measure the mentioned dynamic force. Therefore, the force measurement was replaced by measurement of impulse response to the impact force excited by a hammer, whose tip was fitted by a force sensor. As the goal of these measurements was to evaluate frequency transfer function, the responses at various machine points with respect to a reference point were recorded and analyzed. The reference point was selected at the different location shown in Figure 2.

(i) Knocking test. The natural frequencies of the different components were extracted from the recorded FFT diagram. One accelerometer was connected to the component; the natural frequency data from the FFT graph was recorded by knocking the different components using the impact hammer.

(ii) Operational test. The dominating frequencies were identified considering high values based on the natural frequencies obtain from the knocking test during no-load operating condition. Accelerometers are connected to the components and data were recorded in Auto spectrum graph. The time excitation, the coherence response excitation, and time response excitation were also recorded to investigate the quality of the signal as shown in Figure 3.

Experimental Modal Analysis is based on determining the modal parameters by testing, unlike Analytical Modal Analysis, where the modal parameters are derived from Finite Element Models (FEMs). There are two ways of doing Experimental Modal Analysis: Classical Modal Analysis and 


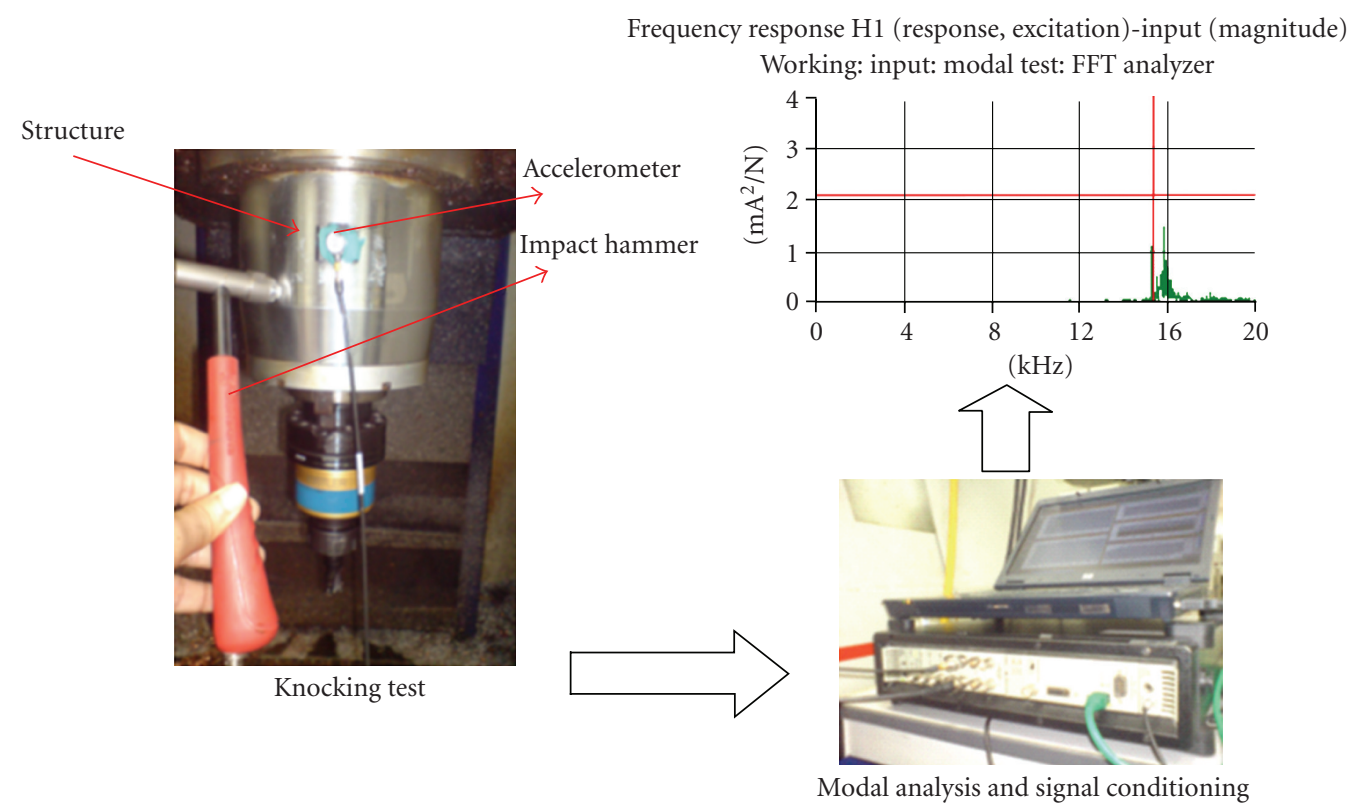

FIGURE 1: Experimental modal analysis test set-up.

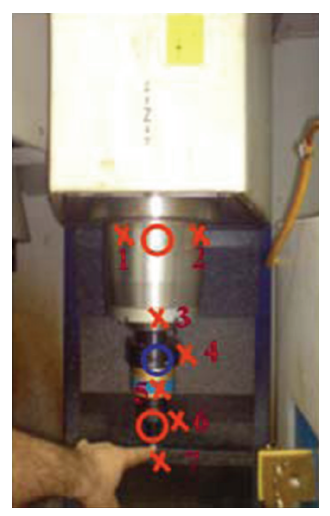

Accelerator position

$\times$ Knocking position

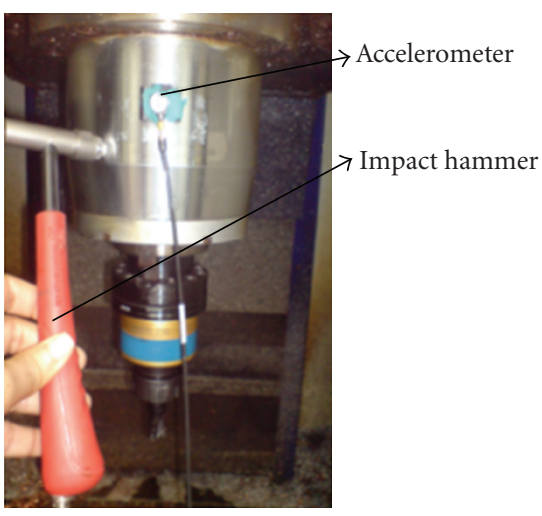

Knocking test

Figure 2: Position of Accelerometer and knocking point at different components of milling machine.

Operational Modal Analysis. In Classical Modal Analysis frequency response functions (or impulse response functions) are calculated from measured input forces and output responses of a structure shown in Figures 3-4. Much of the analysis in modal testing is performed in the frequency domain inside the analyzer. The analyzer task is to convert analog time domain signal into digital frequency domain information compatible with digital computing and then to perform the required computations with these signals. Figures 3-4 indicate the frequency domain information by Fast Fourier Transform for the domination components of vertical machining centre like tool-holder and collet and spindle casing. As it is very difficult to extract the inner spindle mode shape, so operational modal analysis was done for inner spindle.

\section{Operational Modal Analysis}

Operational Modal Analysis is based on measuring only the output of a structure and using the ambient and operating forces as unmeasured input. It is used instead of classical mobility-based modal analysis for accurate modal identification under actual operating conditions, and in situations where it is difficult or impossible to control an artificial excitation of the structure.

In the milling machine structure the inner spindle is surrounded by the outer spindle; as a result it is not possible to extract the mode shape using knocking test. Operational modal analysis was carried out to find out the mode shape of the inner spindle using load and no-load conditions as shown in Figure 5. 
Coherence (response, excitation)-input Working: input: modal test: FFT analyzer

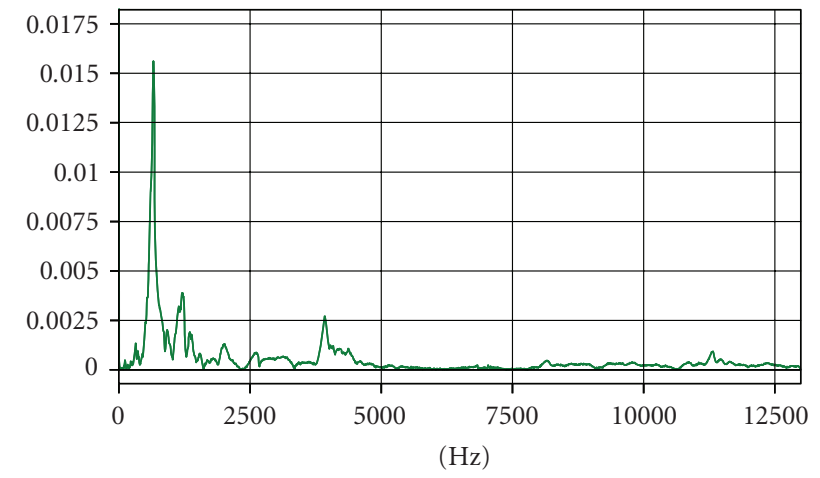

— Y/t chart0

(a)

Time (excitation)-input

Working: input: input: FFT analyzer

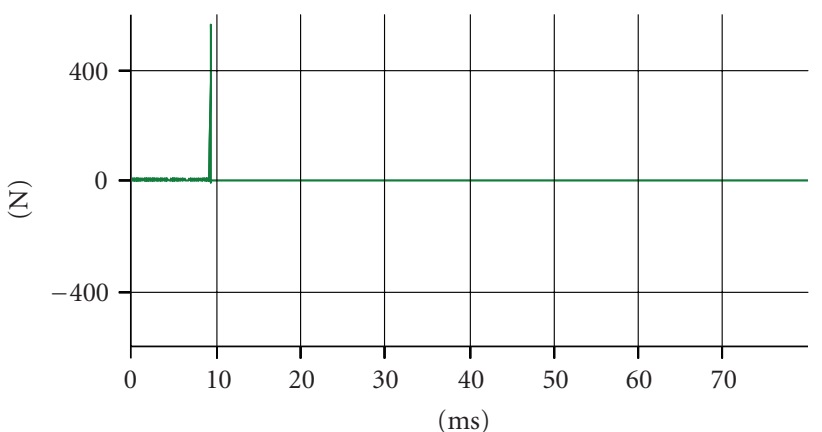

(c)

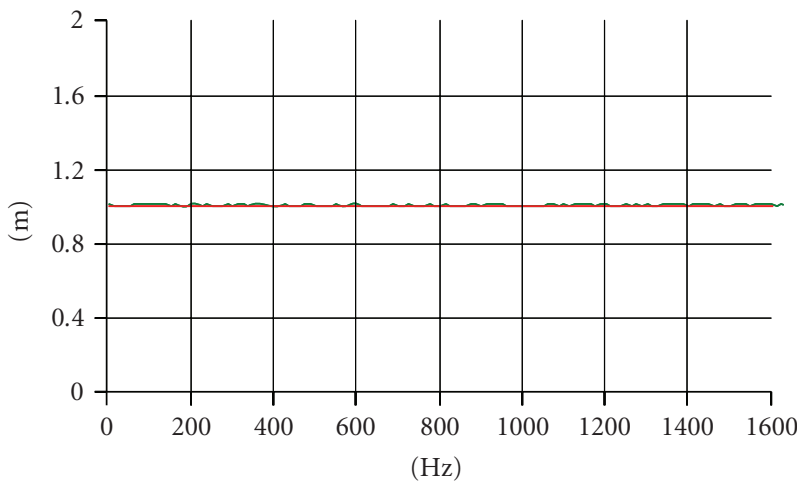

(b)

Time (response)-input

Working: input: input: FFT analyzer

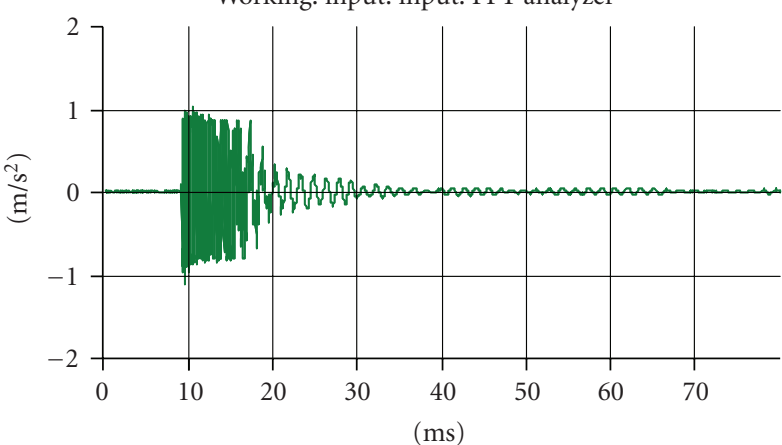

(d)

Figure 3: Experimental modal analysis responses of tool holder.

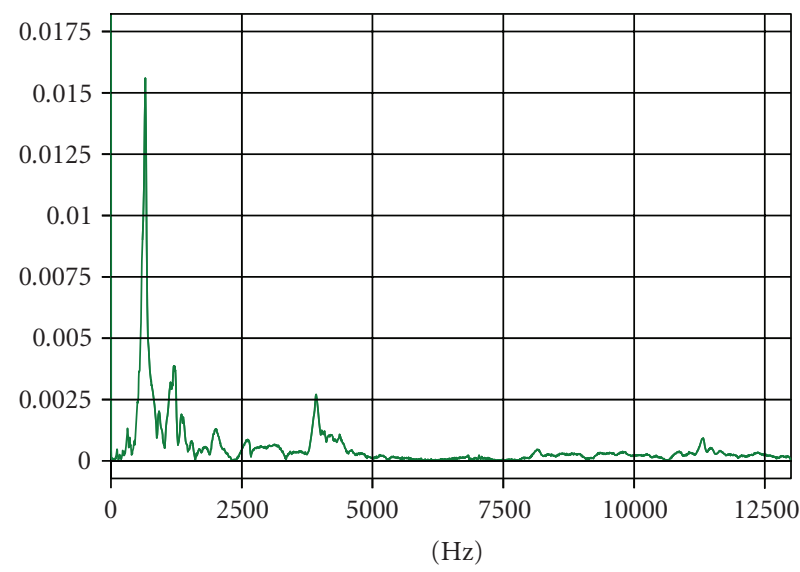

- $\mathrm{Y} / \mathrm{t}$ chart0

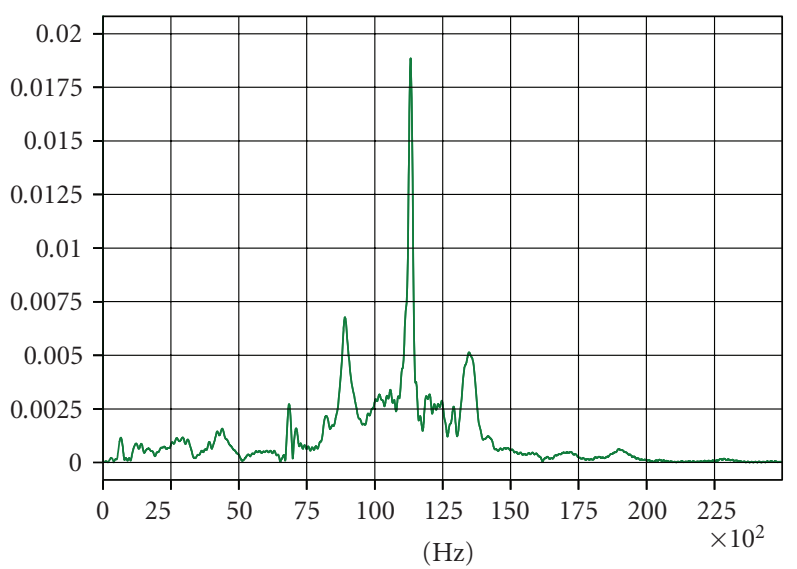

- Y/t chart 0

FIGURE 4: Experimental modal analysis power spectrum responses (FFT); (a) Collet and (b) Spindle casing of vertical machining centre. 


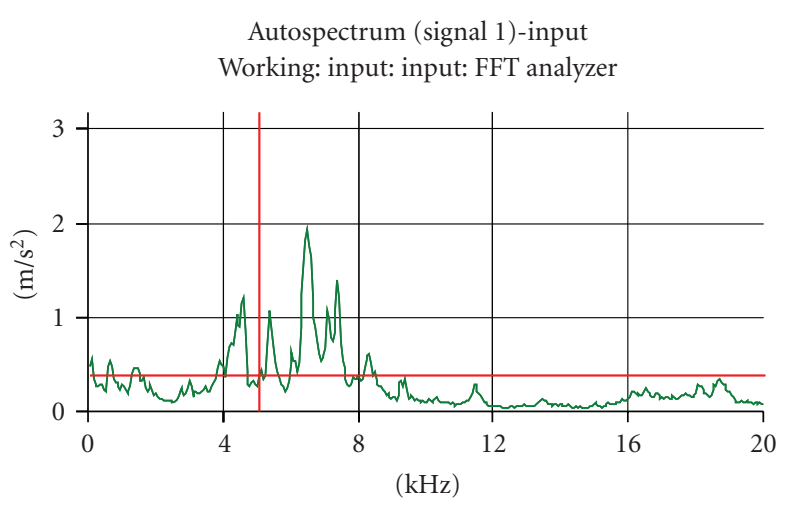

1000 RPM

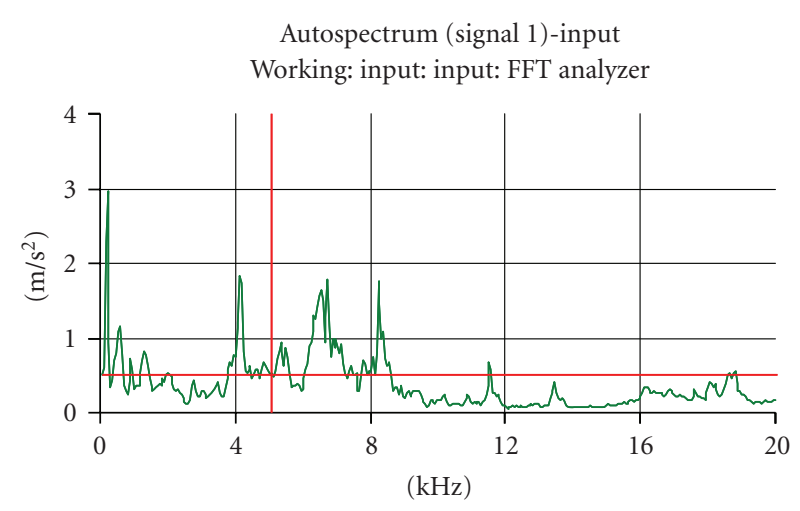

3500 RPM

(a) Inner spindle operational deflection shape with no load. Spindle mode shape: $4394 \mathrm{~Hz}, 6866 \mathrm{~Hz}, 8294 \mathrm{~Hz}$

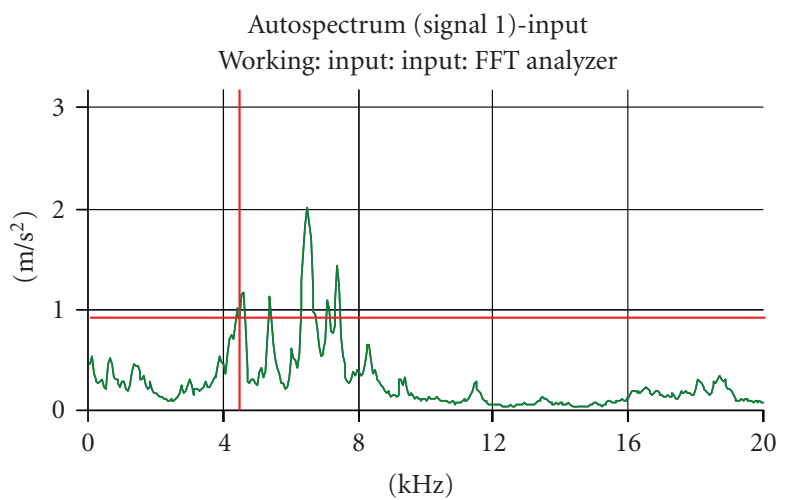

1000 RPM

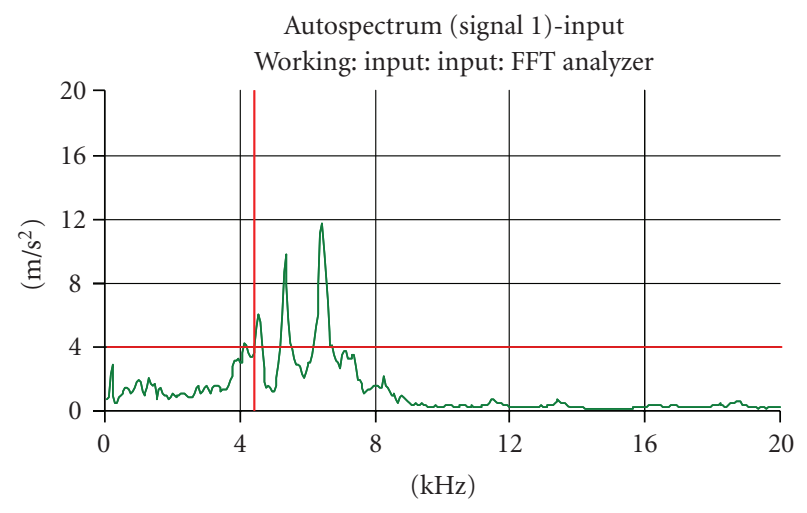

3500 RPM

(b) Inner spindle operational deflection shape with load. Spindle mode shape: $4394 \mathrm{~Hz}, 6866 \mathrm{~Hz}, 8294 \mathrm{~Hz}$

Figure 5: Operational Modal analysis of inner spindle with no-load and load conditions.

\section{Procedures: FE Modeling}

In order to make a finite element model, a three-dimensional geometrical model of machine's structure with CATIA software has been developed and then converted to igs. format for further analysis by ANSYS software. This model provides natural values and response frequency extraction. The observation of vibration modes of machine tool components is three-dimensional shapes which provides better capability to the analysis of vibration model. The model is applied on vertical machining centre. The different components of the machine were measured and designed by CATIA software. The designed models were three-dimensional models. The geometrical model of the machine components is shown in Figure 6. After modeling selection, the necessary input data as material properties such as modulus of elasticity, Poisson ratio, and density are applied. The elements used in the FEM model for mesh generation is quadratic tetrahedral element. The element distribution is uniform to exceed boundary and it is so that in the parts with relatively small dimensions like spindle, tool holder, collet, and so forth. the element dimensions are finer and controlled. Afterwards, boundary conditions on supporting are applied on the earth connection of machine tool and finally modal analysis has been done to obtain natural frequencies. In continuation, fine screening of the finite element model is accomplished to match the natural frequencies results from experimental modal analysis.

\section{FE Modal Analysis}

Modal analysis has been done on the three different components of vertical machining centre using finite element model to determine the natural frequency of machine tool structure elements and to discrete them from each other. These models are as follows:

(i) model number 1: complete model of spindle both outer and inner.

(ii) model number 2: complete model of collet with chuck case.

(iii) model number 3: complete model of tool holder.

\section{Results and Discussion}

A comparison of calculated modes with their measured counterparts is very helpful in general to verify the quality 


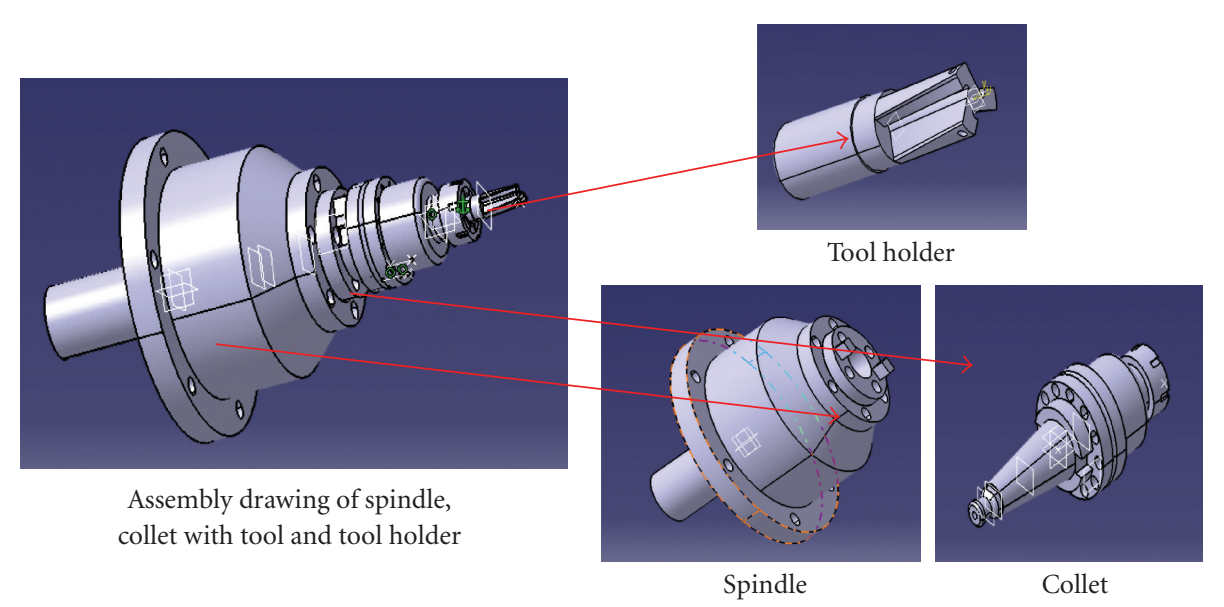

FIgURE 6: CATIA model of the different components of vertical machining centre.

of an FE model for dynamic simulation purposes and to detect any possible improvements. The modal-analyzed natural frequencies of these models via ABAQUS software of different components at different mode shapes are shown in Figures 5-7. The results of analysis of the calculated and experimental mode shape are mentioned in the result analysis section.

Model Number 1: Complete Model of Spindle Both Outer and Inner of Eigen-Frequency Analysis. Finite element analysis of the inner and outer spindle is performed using ABAQUS. The calculated distortions of the each element are shown in Figure 7 at different mode shapes. The elements used in the FEM model for mesh generation are quadratic tetrahedral element. It has been observed from the calculated results that there are five prominent mode shape of the spindle. In most of the mode shape the distortion in the inner spindle is more significant than the outer spindle.

Model Number 2: Complete Model of Collet for EigenFrequency Analysis. Finite element analysis of the collet is again performed using ABAQUS. The calculated distortions of the each element are shown in Figure 8 at different mode shapes.

Model Number 3: The Model of Tool Holder and Selected Eigenmodes of the Components. Finite element analysis of the tool holder was performed using ABAQUS. The calculated distortions of each element are shown in Figure 9 at different mode shapes.

\section{Correlation EMA/FEA}

The natural frequencies obtained from modal analysis of system testing results and FEM are shown in the Tables 1-3. Table 1 shows natural frequencies obtained from the modal analysis of finite element models and modal testing results of spindle both inner and outer and the amount percent of their errors in the different cases.
TABLE 1: Natural frequencies analysis of spindle.

\begin{tabular}{lccccc}
\hline & \multicolumn{3}{c}{ Different major mode shape (Hz) } \\
\hline Spindle & \multicolumn{3}{c}{ Inner Spindle } & \multicolumn{2}{c}{ Outer spindle } \\
\hline Condition & 1 st & 2nd & 3rd & 1 st & 2nd \\
Experimental & 4394 & 6866 & 8294 & 9009 & 11371 \\
Theoretical & 4322 & 6389 & 8004 & 9520 & 10291 \\
Error (\%) & 1.67 & 7.47 & 3.62 & 5.37 & 10.49 \\
\hline
\end{tabular}

TABLE 2: Natural frequencies analysis of Collet.

\begin{tabular}{lcccc}
\hline Collet & \multicolumn{4}{c}{ Different major mode shape $(\mathrm{Hz})$} \\
\hline Condition & 1 st & 2nd & 3rd & 4 th \\
Experimental & 659 & 2032 & 3955 & 5169.7 \\
Theoretical & 770.77 & 2318.9 & 3673.6 & 5318.2 \\
Error(\%) & 14.50 & 12.37 & 7.66 & 2.79 \\
\hline
\end{tabular}

TABLE 3: Natural frequencies analysis of Tool Holder.

\begin{tabular}{lccc}
\hline Tool Holder & & Different major mode shape $(\mathrm{Hz})$ \\
\hline Condition & $1 \mathrm{st}$ & 2nd & 3rd \\
Experimental & 2081 & 8892 & 11352 \\
Theoretical & 2944 & 10099 & 10454 \\
Error $(\%)$ & 29.31 & 11.95 & 8.59 \\
\hline
\end{tabular}

Table 2 shows natural frequencies obtained from the modal analysis of finite element models and modal testing results of collet and the amount percent of their errors in the different cases.

Table 3 shows natural frequencies obtained from the modal analysis of finite element models and modal testing results of tool holder and the amount percent of their errors in the different cases.

The first and second vibration modes of outer spindle are almost similar to the second and third vibration modes of tool holder, respectively. The vibration frequency region of spindle model is much higher than the vibration frequencies of collet model. The percentage error levels for all the 


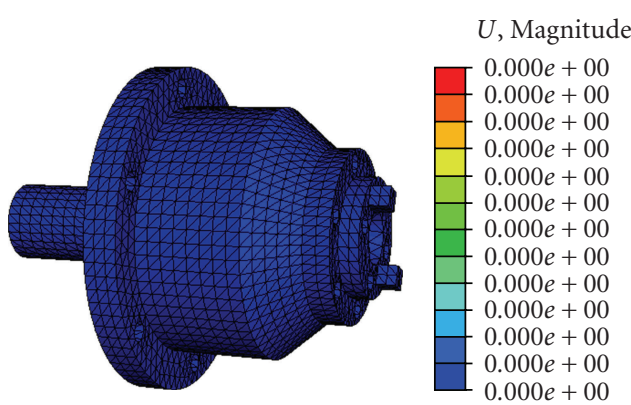

ODB: spindle.odb ABAQUS/standard version $6.6 \times 1$ Wed Jun 04 12:12:56 malay peninsula

Step: Frequency, frequency analysis

Increment $\quad 0$ : Base state

Primary var: $U$, magnitude

Deformed var: $U$ deformation scale factor: $1.000 e+00$

(a) Base state

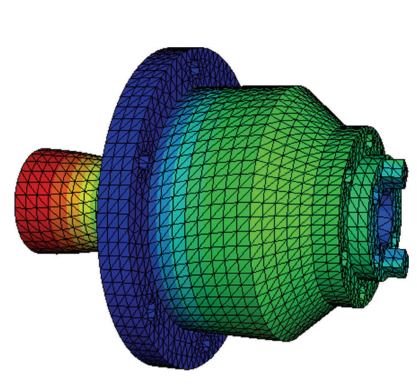

$U$, Magnitude

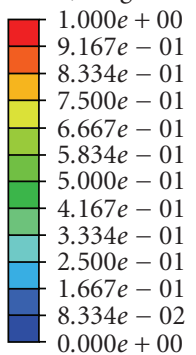

ODB: spindle.odb ABAQUS/standard version $6.6 \times 1$ Wed Jun 04 12:12:56 malay peninsula standard

Step: Frequency, frequency analysis

Mode 6: Value $=1.61157 E+09 \quad$ Freq $=6389.2 \mathrm{cycles} /$ time Primary var: $U$, magnitude

Deformed var: $U$ deformation scale factor: $3.102 e+01$

(c) Mode: $6389 \mathrm{~Hz}$
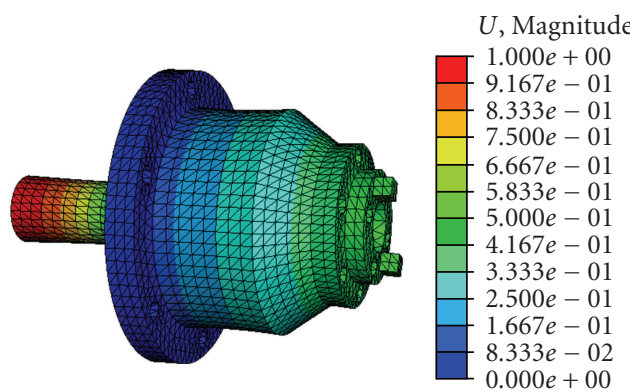

ODB: spindle.odb ABAQUS/standard version $6.6 \times 1$ Wed Jun 04 12:12:56 malay peninsula standard

Step: Frequency, frequency analysis

Mode 10: Value $=3.57864 E+09 \quad$ Freq $=9520.9$ cycles $/$ time Primary var: $U$, magnitude

Deformed var: $U$ deformation scale factor: $3.102 e+01$

(e) Mode: $9520 \mathrm{~Hz}$

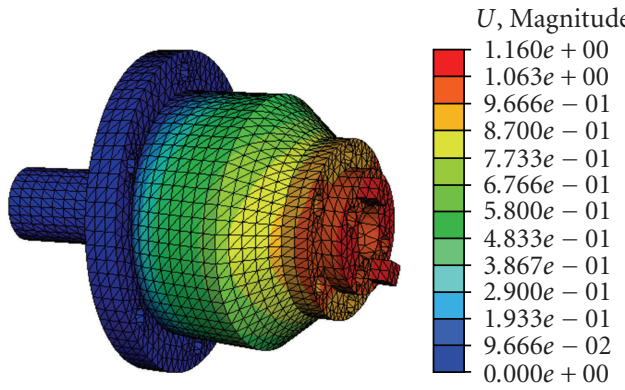

ODB: spindle.odb ABAQUS/standard version $6.6 \times 1$ Wed Jun 04 12:12:56 malay peninsula standard

Step: Frequency, frequency analysis

Mode 4: Value $=7.37518 E+08 \quad$ Freq $=4322.2$ cycles $/$ time

Primary var: $U$, magnitude

Deformed var: $U$ deformation scale factor: $3.102 e+01$

(b) Mode: $4322 \mathrm{~Hz}$

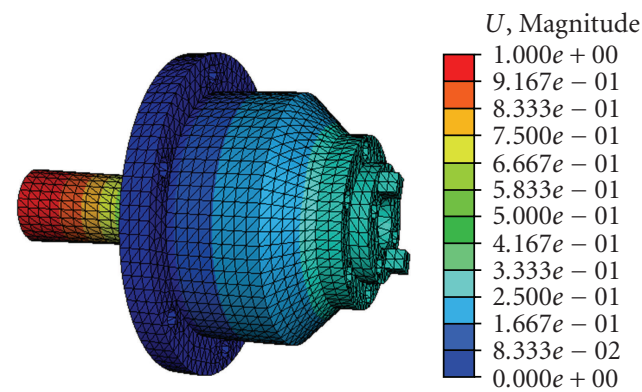

ODB: spindle.odb ABAQUS/standard version $6.6 \times 1$ Wed Jun 04 12:12:56 malay peninsula standard

Step: Frequency, frequency analysis

Mode 7: Value $=2.52912 E+09 \quad$ Freq $=8004$ cycles $/$ time Primary var: $U$, magnitude

Deformed var: $U$ deformation scale factor: $3.102 e+01$

(d) Mode: $8004 \mathrm{~Hz}$

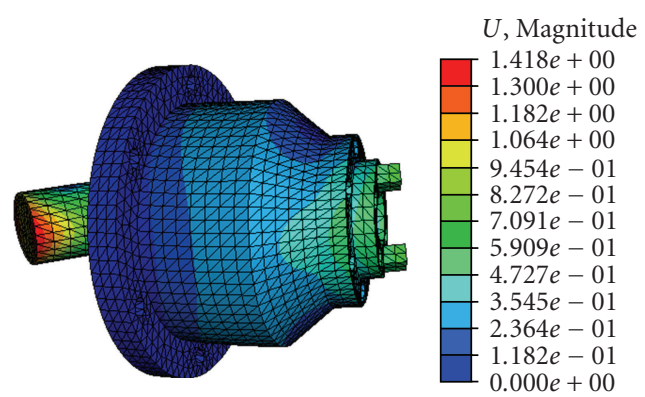

ODB: spindle.odb ABAQUS/standard version $6.6 \times 1$ Thu Jun 05 12:19:22 malay peninsula standard

Step: Frequency, frequency analysis

Mode 12: Value $=4.18066 E+09 \quad$ Freq $=10291 \mathrm{cycles} /$ time

Primary var: $U$, magnitude

Deformed var: $U$ deformation scale factor: $3.102 e+01$

(f) Mode: $10291 \mathrm{~Hz}$

Figure 7: Selected Eigenmodes of the Spindle by FE Analysis. 


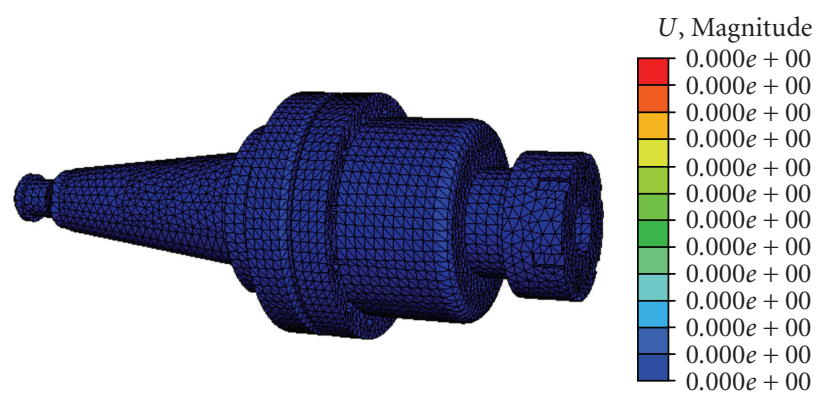

ODB: assembly_spindle.odb ABAQUS/standard version $6.6 \times 1$ Mon Jun 09 18:11:02 malay peninsula standard

Step: Frequency, frequency analysis

Increment 0 : Base state

Primary var: $U$, magnitude

Deformed var: $U$ deformation scale factor: $1.000 e+00$

(a) Base state

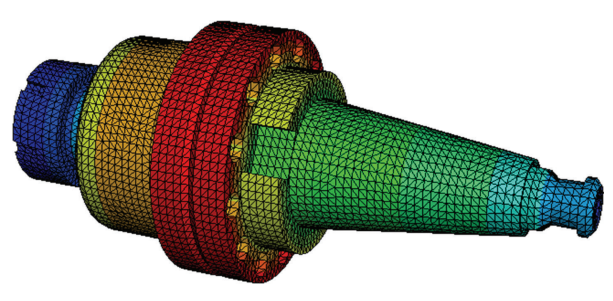

$U$, Magnitude

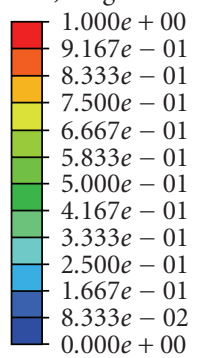

ODB: collet.odb ABAQUS/standard version $6.6 \times 1$

Thu May 22 15:18:55 malay peninsula standard

Step: Frequency analysis, frequency analysis

Mode $3:$ Value $=2.12287 E+08 \quad$ Freq $=2318.9$ cycles $/$ time

Primary var: $U$, magnitude

Deformed var: $U$ deformation scale factor: $2.300 e+01$

(c) Mode: $2318.9 \mathrm{~Hz}$

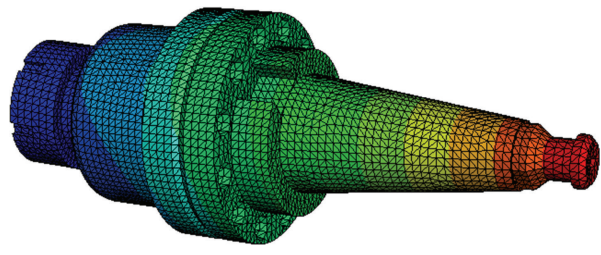

$U$, Magnitude

$1.005 e+00$

$9.215 e-01$

$8.378 e-01$

$7.540 e-01$

$6.702 e-01$

$5.864 e-01$

$5.027 e-01$

$4.189 e-01$

$3.351 e-01$

$2.513 e-01$

$1.676 e-01$

$8.378 e-02$

$0.000 e+00$

ODB: collet.odb ABAQUS/standard version $6.6 \times 1$

Thu May 22 15:18:55 malay peninsula standard

Step: Frequency analysis, frequency analysis

Mode $1:$ Value $=2.34537 E+07 \quad$ Freq $=770.77 \mathrm{cycles} /$ time

Primary var: $U$, magnitude

Deformed var: $U$ deformation scale factor: $2.300 e+01$

(b) Mode: $770.77 \mathrm{~Hz}$

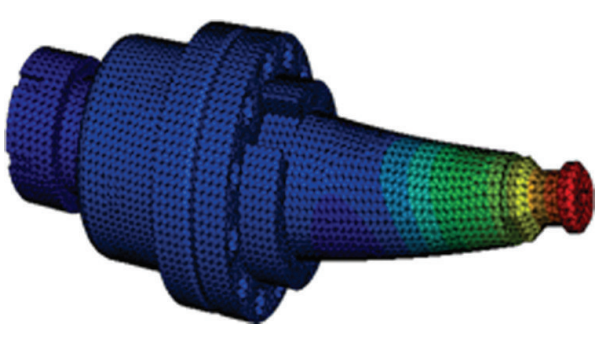

$U$, Magnitude

$1.006 e+00$

$9.224 e-01$

$8.385 e-01$

$7.547 e-01$

$6.708 e-01$

$5.870 e-01$

$5.031 e-01$

$4.193 e-01$

$.354 e-01$
$3.354 e-01$

$2.516 e-01$

$1.677 e-01$

$8.385 e-02$

$0.000 e+00$

ODB: collet.odb ABAQUS/standard version $6.6 \times 1$

Thu May 22 15:18:55 malay peninsula standard

Step: Frequency analysis, frequency analysis

Mode $4:$ Value $=5.32789 E+08 \quad$ Freq $=3673.6$ cycles $/$ time

Primary var: $U$, magnitude

Deformed var: $U$ deformation scale factor: $2.300 e+01$

(d) Mode: $3673.6 \mathrm{~Hz}$

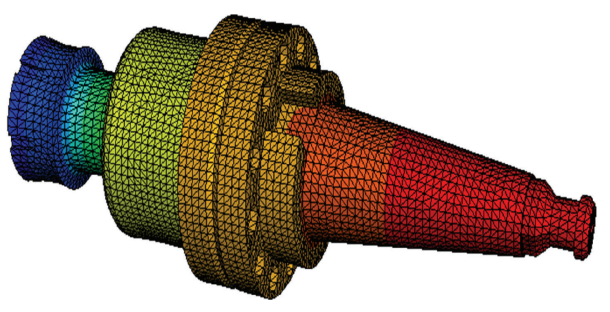

$U$, Magnitude

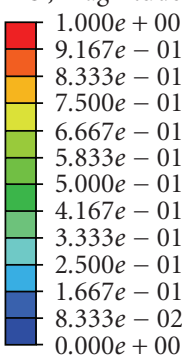

ODB: collet.odb ABAQUS/standard version $6.6 \times 1$

Thu May 22 15:18:55 malay peninsula standard

Step: Frequency analysis, frequency analysis

Mode 6: Value $=1.11659 E+09 \quad$ Freq $=5318.2 \mathrm{cycles} /$ time

Primary var: $U$, magnitude

Deformed var: $U$ deformation scale factor: $2.300 e+01$

(e) Mode: $5318.2 \mathrm{~Hz}$

Figure 8: Selected Eigenmodes of the Collet by FE Analysis. 


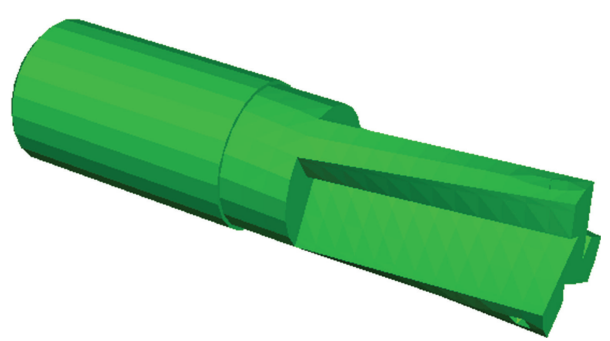

ODB: tool_holder.odb ABAQUS/standard version $6.6 \times 1$ Wed Mar 05 13:26:05 malay peninsula

Step: Frequency, frequency extraction Increment 0: Base state Deformed var: $U$ deformation scale factor: $1.000 e+0$

(a) Base state

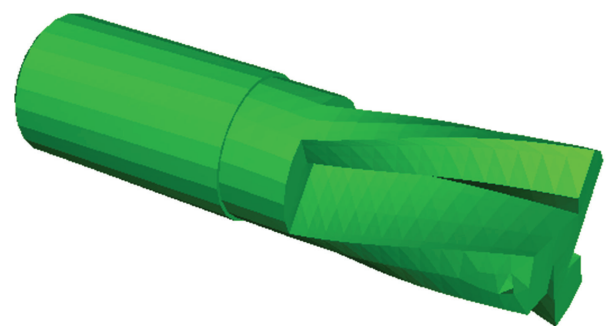

ODB: tool_holder.odb ABAQUS/standard version $6.6 \times 1$ Wed Mar 05 13:26:05 malay peninsula

Step: Frequency, frequency extraction

Mode 3: Value $=4.02660 E+09$ freq $=10099 \mathrm{cycles} /$ time

Deformed var: $U$ deformation scale factor: $8.000 e+0$

(c) Mode: $10099 \mathrm{~Hz}$

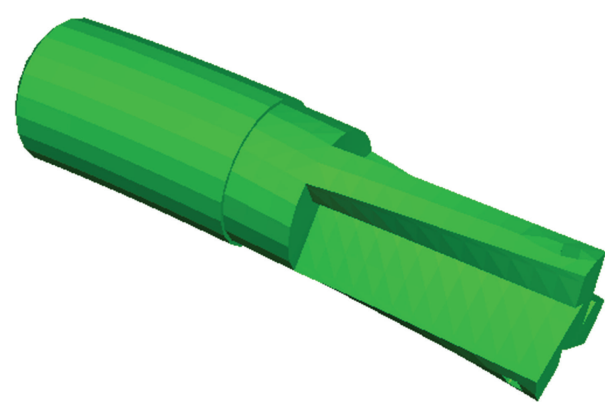

ODB: tool_holder.odb ABAQUS/standard version $6.6 \times 1$ Wed Mar 05 13:26:05 malay peninsula

Step: Frequency, frequency extraction

Mode 1: Value $=3.42154 E+08$ freq $=2944$ cycles $/$ time

Deformed var: $U$ deformation scale factor: $8.000 e+0$

(b) Mode: $2944 \mathrm{~Hz}$

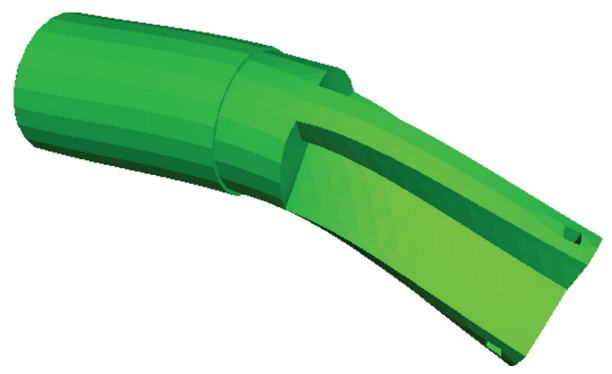

ODB: tool_holder.odb ABAQUS/standard version $6.6 \times 1$ Wed Mar 05 13:26:05 malay peninsula

Step: Frequency, frequency extraction

Mode 4: Value $=4.31477 E+09$ freq $=10454$ cycles $/$ time

Deformed var: $U$ deformation scale factor: $8.000 e+0$

(d) Mode: $10454 \mathrm{~Hz}$

FIgURE 9: Selected Eigenmodes of the Tool Holder by FE Analysis.

components are within the accepted ranges and the high error in some of them might be referred to the boundary conditions specification, because it is not easy to simulate the realistic boundary conditions for such complicated system.

\section{Conclusion}

In this paper a finite element model is used to analyze the mode frequencies and shapes of different machining components and hence compare the results with the experimental one. This model is produced in CATIA software based on the real dimensions of vertical machining centre (model: MCFV 1060LR) machine and analysis was done by ABAQUS software. According to the model analysis, the natural frequencies and vibration modes shape of the model in spindle, collet, and tool holder cases were determined and evaluated. The comparison between natural frequencies of finite element modeling and model testing shows the closeness of the results. From the results, it has been observed that the suitable frequency ranges for end milling will be up to $12000 \mathrm{~Hz}$. This research work will help to find out the natural frequencies of the components and hence predicting the chatter formation zone as resonance phenomena.

\section{References}

[1] D. J. Inman, Engineering Vibration, Prentice-Hall, Englewood Cliffs, NJ, USA, 3rd edition, 2007.

[2] T. C. Huang, Modal Analysis Modeling, Diagnostics and Control-Analytical and Experimental, ASME, New York, NY, USA, 1991.

[3] C. W. de Silva, Vibration and Shock Hand Book, Taylor \& Francis, Boca Raton, Fla, USA, 2005.

[4] N. M. M. Maia and J. M. M. E. Silva, Theoretical and Experimental Modal Analysis, John Wiley \& Sons, New York, NY, USA, 1997.

[5] J. R. Baker and K. E. Rouch, "Use of finite element structural models in analyzing machine tool chatter," Finite Elements in Analysis and Design, vol. 38, no. 11, pp. 1029-1046, 2002. 
[6] J. Lee and D.-H. Kim, "Experimental modal analysis and vibration monitoring of cutting tool support structure," International Journal of Mechanical Sciences, vol. 37, no. 11, pp. 1133-1146, 1995.

[7] Y. Altintas, Manufacturing Automation, Cambridge University Press, London, UK, 2000.

[8] E. Budak and Y. Altintas, "Identification of peripheral milling conditions for improved dimensional accuracy," International Journal of Machine Tools and Manufacture, vol. 34, no. 7, pp. 907-918, 1994.

[9] J. Tlusty and M. Polacek, "The stability of machine tools against self excited vibration in machining," in Proceedings of International Research in Production Engineering, pp. 465-474, ASME, Pittsburgh, Pa, USA, 1963.

[10] N. V. Talantov, A. K. M. N. Amin, and N. P. Chereomushnikov, "Temperature deformation laws of chatter formation during metal cutting process," in Proceedings of the 5th Soviet National Conference "Teplophysika Technologichieskikh Processov,", p. 92, Volgograd, Russia, 1980.

[11] A. K. M. N. Amin, "Investigation of the mechanism of chatter formation during metal cutting process," Mechanical Engineering Bulletin, vol. 6, no. 1, pp. 11-18, 1983.

[12] A. K. M. N. Amin, Investigation of the laws governing the formation of chatter during metal cutting processes and the influence of chatter on tool wear, Ph.D. thesis, Georgian Polytechnic Institute, Atlanta, Ga, USA, 1982. 

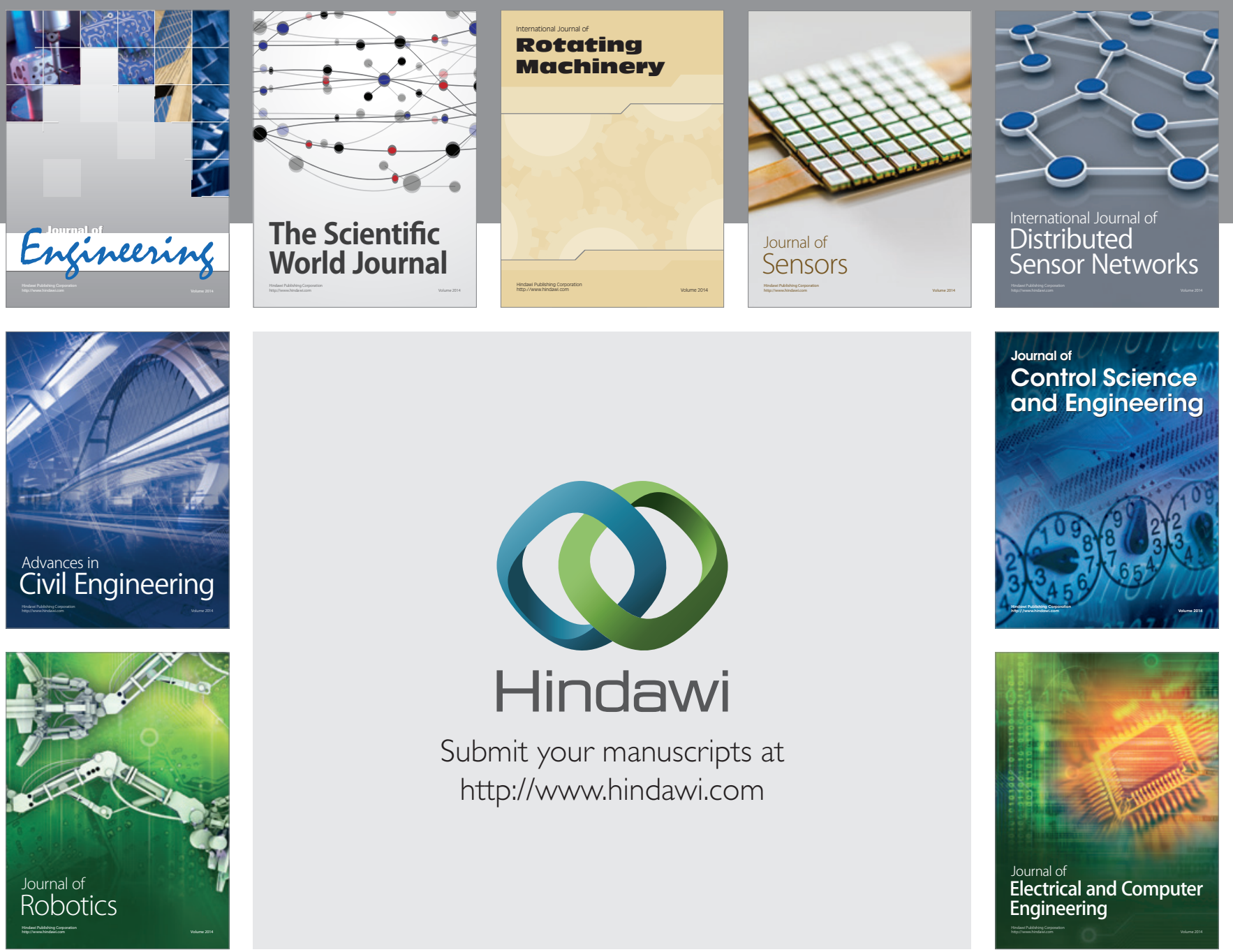

Submit your manuscripts at

http://www.hindawi.com
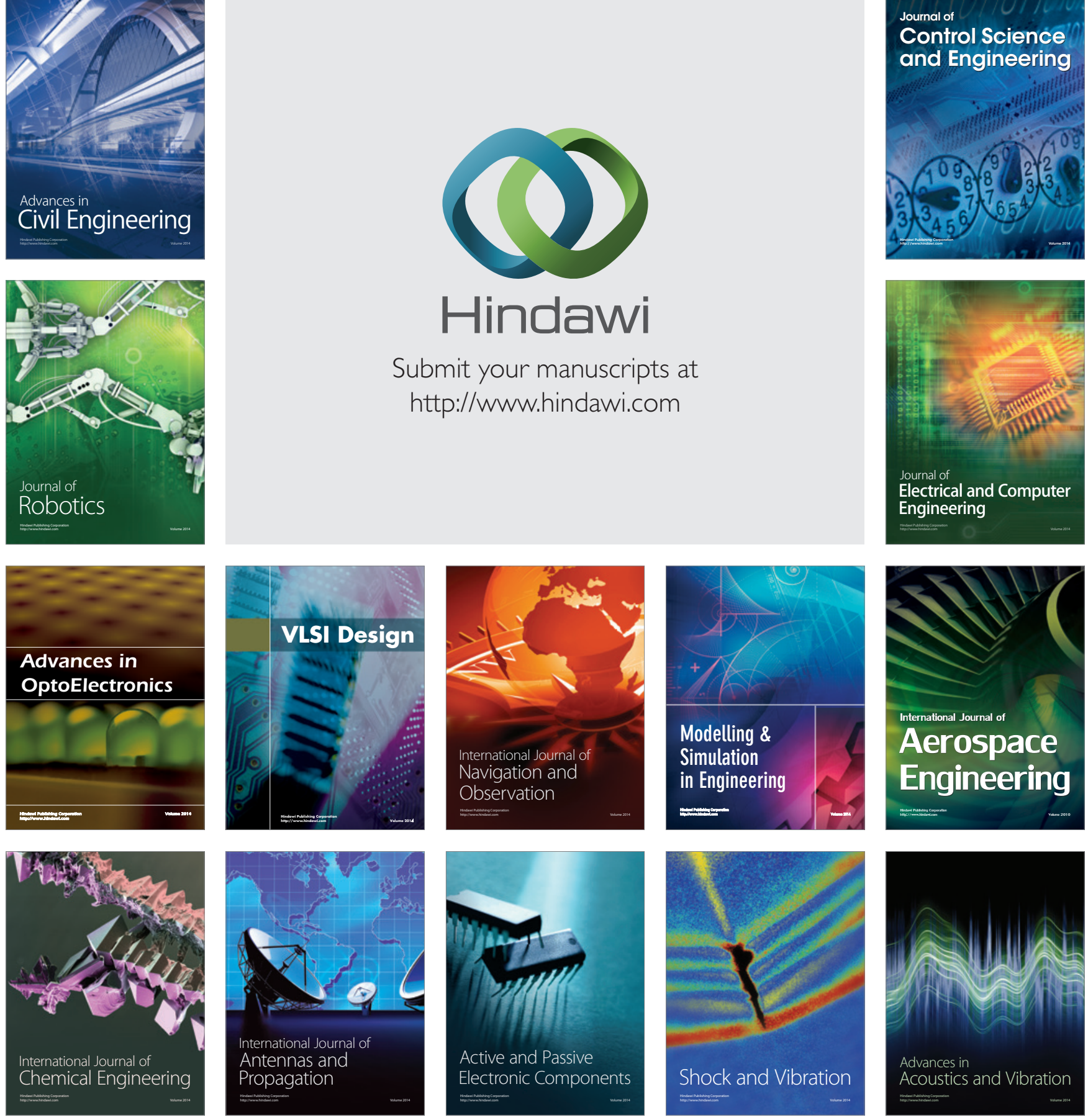